Asia Pac. J. Math. 2020 7:26

ASIA PACIFTC ACADEMIC

\title{
CODING TECHNIQUE WITH WEB GRAPH AND DIFFERENCE CORDIAL LABELING
}

\author{
G. UMA MAHESWARI ${ }^{1}$, M.S. UMAMAHESWARI ${ }^{1,2}$, SUZAN JABBAR OBAIYS ${ }^{3, *}$ \\ ${ }^{1}$ Department of Mathematics, Dhanalakshmi Srinivasan College of Engineering and Technology, \\ Mamallapuram, ECR, Chennai - 603104, Tamil Nadu, India \\ ${ }^{2}$ Coimbatore Marine College, Myleripalayam, Coimbatore - 641032, Tamil Nadu, India \\ ${ }^{3}$ School of Mathematical and Computer Science, Heriot-Watt University, Malaysia \\ *Corresponding author: S.Obaiys@hw.ac.uk
}

Received May 20, 2020

\begin{abstract}
Aвstract. In this paper, a technique of coding a text message using web graph $W(t, n)$ by applying Difference cordial labeling is provided. The method of passing the secret message in the form of matrix code also three illustrations using one method of numbering of alphabets for three messages are dealt with in detail in this paper. The catchy clue to guess the graph, mathematical or non mathematical is given for finding suitable web graph $W(t, n)$ to maintain secrecy.
\end{abstract}

2010 Mathematics Subject Classification. 05C78.

Key words and phrases. web graph; DDCC; difference cordial labeling.

\section{InTRODUCTION}

Many family secrets are maintained by using a mutually agreed upon construct (an official family story) when speaking with outside members. Agreement to maintain the secret is often coerced through shaming and reference to family honor. Present day military forces of an informational society conduct intense and complicated communicating activities on a daily basis, using modern telecommunications and computing methods. In the context of cryptography the graph problems are usually trivial but sometimes by suitable generalization they can suggest concepts which are not only nontrivial but which may even be of some interest and few examples are given by R. C. Read and network security with cryptography

DOI: $10.28924 /$ APJM/7-26

(92020 Asia Pacific Journal of Mathematics 
was initialized by [1], [2], [3], [4], [5]. Cryptography is the study of methods of converting messages to a form unreadable except to one who knows how to decrypt them. Here we introduce method of converting text messages in to a matrix form except to one who knows difference cordial labeling of the web graph $W(t, n)$ to decode them.

In united states military communication systems, commercial refile refers to sending a military message via a commercial communications network. The message may come from a military network, such as tap relay network, a point-to-point telegraph network, a radio telegraph network or the defense switched network. But here we are given a technique of coding a message without any computer network, we dedicate this article to International Army. Koh et al., defined a Web graph and Ponraj et al., have introduced Difference Cordial labeling of graphs [6]. Uma Maheswari et al., have introduced coding through a two star and three star graph with super mean labeling [7], [8] and Fibonacci web with difference cordial labeling [9]. Authenticated key Distribution Using graphs was given by [10] [11], In 2012 edge product cordial labeling on wheel, cycle and helm were presented by a paper by Vaidya [12]. Motivated by these, we worked on web graphs $W(3,3), W(3,6)$ and $W(3,7)$ by applying difference cordial labeling and GMJ (Graph Message Jumbled) coding method and hence this paper.

\section{Difference Cordial Labeling:}

Let $G$ be a $(p, q)$ graph.Let $f: V(G) \rightarrow\{1,2, \cdots, p\}$.For each edge $e=u v$, assign the label $|f(u)-f(v)|$. Then $f$ is called difference cordial labeling if $f$ is one to one and $\left|e_{f}(0)-e_{f}(1)\right| \leq 1$ where $e_{f}(1)$ and $e_{f}(0)$ denote the number of edges labeled with 1 and not labeled with 1 respectively.A graph with a difference cordial labeling is called a difference cordial graph .

Coding Method and procedure for encoding a message referred by [9].

\subsection{Numbering of alphabets: DDCC :}

\section{Clue: Difference Cordial}

Numbering is alternated cordially using THREE, the difference in the number of letters of the words DIFFERENCE and CORDI AL. Starting from the First set of three alphabets $(A, B, C)$ which take the numbers $(1,2,3)$, then to the first set of three alphabets $(X, Y, Z)$ which takes the numbers $(4,5,6)$, then to the second set of three alphabets from the back $(D, E, F)$ which takes the number $(7,8,9)$, and so on, the numbering is done justifying the words DIFFERENCE and $C O R D I A L$ (movement from front and back done smoothly giving equal importance and hence 'cordial'). Hence this method is named as DDCCorDCDC. 


$\begin{array}{ccccccccccccc}1 & 2 & 3 & 7 & 8 & 9 & 13 & 14 & 15 & 19 & 20 & 21 & 25 \\ \text { A } & \text { B } & \text { C } & \text { D } & \text { E } & \text { F } & \text { G } & \text { H } & \text { I } & \text { J } & \text { K } & \text { L } & \text { M } \\ 26 & 22 & 23 & 24 & 16 & 17 & 18 & 10 & 11 & 12 & 4 & 5 & 6 \\ \text { N } & \text { O } & \text { P } & \text { Q } & \text { R } & \text { S } & \text { T } & \text { U } & \text { V } & \text { W } & \text { X } & \text { Y } & \text { Z }\end{array}$

The function for encoding is given below:

The rule for triplets of alphabets from the begining is

$g\left(a_{(3(k-1)+i)}\right)=i+3 \ell, i=1,2,3 \quad\{(k, \ell) /(8,0)(7,2)(6,4)(5,6)\}$

The rule for triplets of alphabets from the back is

$g\left(a_{(3 k+i)}\right)=i+3 \ell, \quad i=1,2,3 \quad\{(k, \ell) /(0,1)(3,7)(1,3)(2,5)\}$

Two letters $\mathrm{M}$ and $\mathrm{N}$ are not included in the triplets for them the rule is $g\left(a_{(3 k+i)}\right)=i+3 \ell, \quad i=1,2 \quad\{(k, \ell) /(4,8)\}$

1.2. Coding a letter. The center gets the largest number and is denoted by $a_{0,0}$, If the number corresponding to the center is less than 26 , then the number next to it is denoted by $a_{0,1}$ and so on. The number of vertices in the web $W(t, n)$ is $(t+1) n+1$.If $s>26$, assigned to a vertex, the letter corresponds to the number $s$ is the same as the letter corresponding to the number $t$ where $s \cong \operatorname{tmod} 26$.

(i) Let $a_{i, j}$ denote the number assigned to $j^{\text {th }}$ vertex in the $i^{\text {th }}$ string of vertices $i=$ $1,2,3, \cdots, n$ and $j=1,2,3, \cdots,(n+1)$.

(ii) Let $b_{i, j}$ denote the number assigned to $j^{\text {th }}$ edge along $i^{\text {th }}$ string of vertices $i=1,2,3, \cdots, n$ and $j=1,2,3, \cdots,(n+1)$.

(iii) Let $c_{i, k}$ correspond to the number assigned to the $k^{\text {th }}$ edge of the $i^{\text {th }}$ cycle $i=1,2,3, \cdots, n$ and $k=1,2,3, \cdots, n$.

1.3. Labeling: The difference cordial labeling done for $W(3,6)$ is shown below:

Some observations on difference cordial labeling on web $W(t, n)$ are listed. Here $W(t, n)$ represents the web with $n$ number of vertices in a cycle and $t$ number of such cycles. That is $W(t, n)$ is a web in general with $t$ number of $C_{n}$ cycles. Note that $W(1, n)$ is a helm and $W(2, n)$ is a web. If $\mathrm{n}$ is even, on the outer cycle,number any vertex as 1 and this fixes the first string of vertices $s a_{1}$. Moving along the clockwise directions the other strings are denoted by $s a_{2}, s a_{3}$ and so on. The pendant vertex on $S V_{1}$ which is got by moving out is given the number 2 .The 
pendant vertex in the next string $S V_{2}$ is given the number 3 . Then moving into and moving along the outer cycle and repeating the process the vertices are numbered.

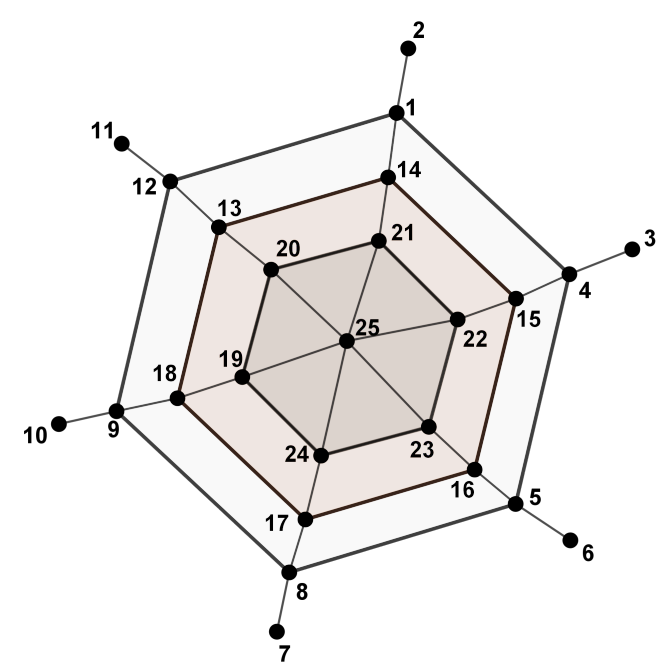

Figure 1. web $W(3,6)$

1.4. Labeling: The difference cordial labeling done for $W(3,7)$ is shown below: Take any string of vertices and assign the number 1 to its pendant vertex.This string is the first string of vertices denoted by $s a_{1}$.The other strings are numbered as $s a_{2}, s a_{3}$ and so on by moving in clockwise direction. From the pendant vertex numbered 1 move into and number the adjacent vertex as 2.Then move along the outer cycle to the next adjacent vertex numbering it as 3 and move out to the pendant vertex,numbering it as 4.Then the pendant vertex in the next string (jump from pendant vertex to pendant vertex) is given the number 5. Move into and number the adjacent vertex and move along the outer cycle. Repeat this pattern and reach to the apex vertex $K_{1}$.

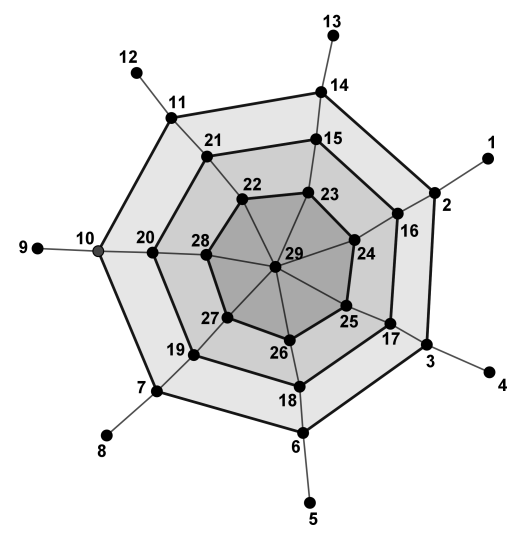

Figure 2. web $W(3,7)$ 


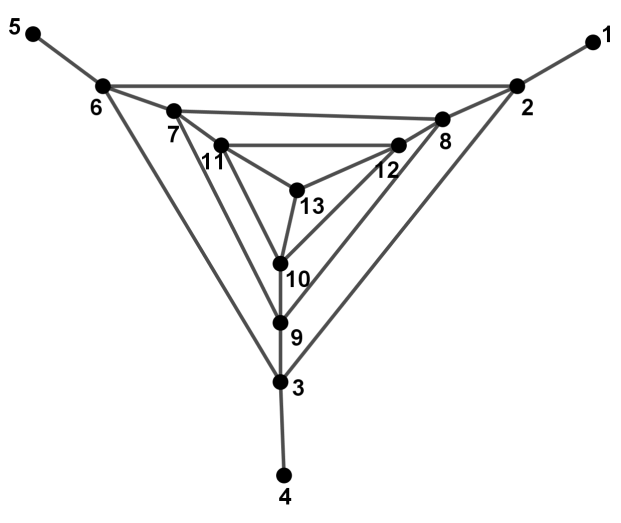

FigURE 3. web $W(3,3)$

A soldier of the International Army received a message which shows in the matrices with the text message "The White Army stood still, while the black Army dashed", what is the message contain with the matrix require an additional information on a certain thing but the information regarding to what that thing is already give. The final answer will be in the text form (words). Recently there have been many efforts to improve coding systems for digital images and speech signals. Among the various techniques, a picture coding method of the present invention codes a picture signal and a ratio of a number of luminance pixels and a number of chrominance pixels for the picture signal, and then one coding method out of at least two coding methods is selected depending on the ratio. Next data related to a picture size is coded in accordance with the selected coding method. The data related to the picture size indicates a size of the picture corresponding to the picture signal or an output area, which is a pixel area to be outputted in decoding in a whole pixel area coded in the picture signal coding here we introduce mathematical coding technique called matrix coding method.

The following illustration shows that how the text message is transformed to coded message in stepwise it is known as encoding a message and web graph $W(3,6)$ is used by applying Difference Cordial Labeling is shown in Fig 1, and the letter codes are shuffled as there are 45 letters in the message we proceed as follows. The last three letters whose positions are $43^{r d}, 44^{\text {th }}$ and $45^{\text {th }}$ are written first.Then the first three letters whose positions are $1^{\text {st }}, 2^{\text {nd }}$ and $3^{r d}$ are written. Maintain the same difference and moving cordially from the back and from the front, the letter codes are presented in a horizontal string. $43^{\text {rd }}, 44^{\text {th }}, 45^{\text {th }}, 1^{\text {st }}, 2^{\text {nd }}, 3^{\text {rd }}, 40^{\text {th }}, 41^{\text {th }}, 42^{\text {th }}, 4^{\text {th }}, 5^{\text {th }}$, and $6^{\text {th }}$ etc. 


\begin{tabular}{|c|c|}
\hline plain text & cipher text \\
\hline Message & $\begin{array}{l}\text { The White Army stood still, } \\
\text { while the black Army dashed }\end{array}$ \\
\hline clue & Site or house with odd and even wings. \\
\hline Graph & The web graph $W(3,6)$ is considered, (Fig 1$)$ \\
\hline Coding(word wise) & Letter Codes \\
\hline The & $a_{5,3} a_{3,1} a_{4,2}$ \\
\hline White & $a_{6,2} a_{3,1} a_{2,3} a_{5,3} a_{4,2}$ \\
\hline Army & $a_{1,2} a_{3,3} a_{0,0} c_{1,4}$ \\
\hline stood & $a_{4,3} a_{5,3} a_{2,4} a_{2,4} a_{6,3}$ \\
\hline still & $a_{4,3} a_{5,3} a_{2,3} a_{1,4} a_{1,4}$ \\
\hline while & $a_{6,2} a_{3,1} a_{2,3} a_{1,4} a_{4,2}$ \\
\hline the & $a_{5,3} a_{3,1} a_{4,2}$ \\
\hline black & $a_{1,1} a_{1,4} a_{1,2} a_{2,1} a_{6,4}$ \\
\hline Army & $a_{1,2} V_{3,3} a_{0,0} c_{1,4}$ \\
\hline dashed & $a_{4,1} a_{1,2} a_{4,3} a_{3,1} a_{4,2} b_{6,3}$ \\
\hline Presenting the letter codes & $43^{r d}, 44^{t h}, 45^{t h}$ then $1^{s t}, 2^{n d}, 3^{r d}$ and so on. \\
\hline Horizontal string & $\begin{array}{lll}a_{3,1} a_{4,2} b_{6,3} & a_{5,3} a_{3,1} a_{4,2} & b_{6,3} a_{1,2} a_{4,3} \\
a_{6,2} a_{3,1} a_{2,3} & a_{3,3} a_{0,0} c_{1,4} & a_{5,3} a_{4,2} a_{1,2} \\
a_{2,1} a_{6,4} a_{1,2} & a_{3,3} a_{0,0} c_{1,4} & a_{1,1} a_{1,4} a_{1,2} \\
a_{4,3} a_{5,3} a_{2,4} & a_{5,3} a_{3,1} a_{4,2} & a_{2,4} b_{6,3} a_{4,3} \\
a_{2,3} a_{1,4} a_{4,2} & a_{5,3} a_{2,3} a_{1,4} & a_{1,4} a_{6,2} a_{3,1}\end{array}$ \\
\hline Result (Matrix code) & $\left(\begin{array}{ccc}a_{3,1} a_{4,2} b_{6,3} & a_{5,3} a_{3,1} a_{4,2} & b_{6,3} a_{1,2} a_{4,3} \\
a_{6,2} a_{3,1} a_{2,3} & a_{3,3} a_{0,0} c_{1,4} & a_{5,3} a_{4,2} a_{1,2} \\
a_{2,1} a_{6,4} a_{1,2} & a_{3,3} a_{0,0} c_{1,4} & a_{1,1} a_{1,4} a_{1,2} \\
a_{4,3} a_{5,3} a_{2,4} & a_{5,3} a_{3,1} a_{4,2} & a_{2,4} b_{6,3} a_{4,3} \\
a_{2,3} a_{1,4} a_{4,2} & a_{5,3} a_{2,3} a_{1,4} & a_{1,4} a_{6,2} a_{3,1}\end{array}\right)$ \\
\hline
\end{tabular}

The decoding can be done as follows. Counting the number of codes, the number of letters in the message(here it is 45) can be found out.

Drawing a diagram with 45 boxes and filling up the boxes with the letters in the above order the message gets decoded. The Horizontal string is written in accordance with the numbering of alphabets (DDCC).

The second illustration also shows the same technique and web graph $W(3,7)$ by applying Difference Cordial Labeling is shown in Fig 2, and the letter codes are shuffled as there are 60 letters in the message we proceed as follows. The last three letters whose positions are 
$58^{\text {th }}, 59^{\text {th }}$ and $60^{\text {th }}$ are written first.Then the first three letters whose positions are $1^{\text {st }}, 2^{\text {nd }}$ and $3^{\text {rd }}$ are written. Maintain the same difference and moving cordially from the back and from the front,the letter codes are presented in a horizontal string. $58^{\text {th }}, 59^{\text {th }}, 60^{\text {th }}, 1^{\text {st }}, 2^{\text {nd }}, 3^{\text {rd }}, 55^{\text {th }}, 56^{\text {th }}, 57^{\text {th }}, 4^{\text {th }}, 5^{\text {th }}$, and $6^{\text {th }}$ etc. Counting the number of codes, the number of letters in the message (here it is 60 ) can be found out. Here, there are only vertex notations, it is possible to denote edge and cycle notations also.

\begin{tabular}{|c|c|}
\hline plain text & cipher text \\
\hline Message & $\begin{array}{l}\text { Army declares bankruptcy, appoints navy } \\
\text { admiral as emergency managers }\end{array}$ \\
\hline clue & Site or house with odd and odd wings \\
\hline Graph & The web graph $W(3,7)$ is considered, (Fig 2). \\
\hline Coding(word wise) & Letter Codes \\
\hline Army & $a_{1,1} a_{1,3,} a_{2,4} a_{3,1}$ \\
\hline declares & $a_{4,2} a_{4,1} a_{2,2} a_{6,3} a_{1,1} a_{1,3} a_{4,1} a_{2,3}$ \\
\hline bankruptcy & $a_{1,2} a_{1,1} a_{3,4} a_{5,3} a_{1,3} a_{5,2} a_{7,4} a_{3,3} a_{2,2} a_{3,1}$ \\
\hline appoints & $a_{1,1} a_{7,4} a_{7,4} a_{6,4} a_{7,3} a_{3,4} a_{3,3} a_{2,3}$ \\
\hline navy & $a_{3,4} a_{1,1} a_{6,2} a_{3,1}$ \\
\hline admiral & $a_{1,1} a_{4,2} a_{2,4} a_{7,3} a_{1,3} a_{1,1} a_{6,3}$ \\
\hline as & $a_{1,1} a_{2,3}$ \\
\hline emergency & $a_{4,1} a_{2,4} a_{4,1} a_{1,3} a_{7,1} a_{4,1} a_{3,4} a_{2,2} a_{3,1}$ \\
\hline managers & $a_{2,4} a_{1,1} a_{3,4} a_{1,1} a_{7,1} a_{4,1} a_{1,3}$ \\
\hline Presenting the letter codes & $58^{\text {th }}, 59^{\text {th }}, 60^{\text {th }}, 1^{\text {st }}, 2^{\text {nd }}, 3^{\text {rd }}$ and so on. \\
\hline Horizontal string & $\begin{array}{cccc}a_{4,1} a_{1,3} a_{2,3} & a_{1,1} a_{1,3} a_{2,4} & a_{3,4} a_{1,1} a_{7,1} & a_{3,1} a_{4,2} a_{4,1} \\
a_{3,1} a_{2,4} a_{1,1} & a_{2,2} a_{6,3} a_{1,1} & a_{4,1} a_{3,4} a_{2,2} & a_{1,3} a_{4,1} a_{2,3} \\
a_{4,1} a_{1,3} a_{7,1} & a_{1,2} a_{1,1} a_{3,4} & a_{2,3} a_{4,1} a_{2,4} & a_{5,3} a_{1,3} a_{5,2} \\
a_{1,1} a_{6,3} a_{1,1} & a_{7,4} a_{3,3} a_{2,2} & a_{2,4} a_{7,3} a_{1,3} & a_{3,1} a_{1,1} a_{7,4} \\
a_{3,1} a_{1,1} a_{4,2} & a_{7,4} a_{6,4} a_{7,3} & a_{3,4} a_{1,1} a_{6,2} & a_{3,4} a_{3,3} a_{2,3}\end{array}$ \\
\hline Result (Matrix Code) & $\begin{array}{rrrr}a_{4,1} a_{1,3} a_{2,3} & a_{1,1} a_{1,3} a_{2,4} & a_{3,4} a_{1,1} a_{7,1} & a_{3,1} a_{4,2} a_{4,1} \\
a_{3,1} a_{2,4} a_{1,1} & a_{2,2} a_{6,3} a_{1,1} & a_{4,1} a_{3,4} a_{2,2} & a_{1,3} a_{4,1} a_{2,3} \\
a_{4,1} a_{1,3} a_{7,1} & a_{1,2} a_{1,1} a_{3,4} & a_{2,3} a_{4,1} a_{2,4} & a_{5,3} a_{1,3} a_{5,2} \\
a_{1,1} a_{6,3} a_{1,1} & a_{7,4} a_{3,3} a_{2,2} & a_{2,4} a_{7,3} a_{1,3} & a_{3,1} a_{1,1} a_{7,4} \\
a_{3,1} a_{1,1} a_{4,2} & a_{7,4} a_{6,4} a_{7,3} & a_{3,4} a_{1,1} a_{6,2} & a_{3,4} a_{3,3} a_{2,3}\end{array}$ \\
\hline
\end{tabular}

The third illustration follows the labeling and clue as in the previous illustration. The letter codes are shuffled as there are 11 letters in the message we proceed as follows. The first three letters whose positions are $1^{\text {st }}, 2^{\text {nd }}$ and $3^{\text {rd }}$ are written first.Then the last three letters whose 
positions are $9^{\text {th }}, 10^{\text {th }}$ and $11^{\text {th }}$ are written next. Maintain the same difference and moving cordially from the front and from the back,the letter codes are presented in a horizontal string.

\begin{tabular}{|c|c|}
\hline plain text & cipher text \\
\hline Message & Stop be alert \\
\hline Graph & The web graph $W(3,3)$ is considered, (Fig 3). \\
\hline Coding(word wise & Letter Codes \\
\hline Stop & $a_{0,4} a_{0,5} a_{0,9} a_{0,10}$ \\
\hline be & $c_{3,1} a_{1,4}$ \\
\hline alert & $b_{2,1} a_{0,8} a_{1,3} a_{0,3} a_{1,3} a_{0,5}$ \\
\hline Presenting the letter codes & $1^{s t} 2^{n d}$ and $3^{r d}$ then $9^{t h}, 10^{t h}$ and $11^{t h}$ so on. \\
\hline Horizontal string & $a_{0,4} a_{0,5} a_{0,9} \quad \begin{array}{c}a_{1,3} a_{0,3} a_{0,5} \quad a_{0,10} c_{3,1} 0(0,0) \\
a_{1,3} b_{2,1} a_{0,8}\end{array}$ \\
\hline Result (Matrix Code) & $\left(\begin{array}{c}a_{0,4} a_{0,5} a_{0,9} \\
a_{1,3} a_{0,3} a_{0,5} \\
a_{0,10} c_{3,1} 0(0,0)\end{array}\right.$ \\
\hline
\end{tabular}

\section{Algorithm}

- step 1: Web graph has to be taken using clue.

- step 2: Apply Difference cordial labeling on the Web graph $W(t, n)$.

- step 3: Split the alphabets using DDCC.

- step 4: Method of coding for each letter is stated.

- step 5: The message to be coded is written.

- step 6: coding wordwise.

- step 7: Representing codes into string using DDCC.

- step 8: Representing string into matrix form.

The sender has to forward to the receiver the following:

- Clue to guess the graph 
- Clue to guess the numbering of alphabets without explanation.

- Letter codes along a matrix

\section{CONCLUSion AND FUtURE WORK:}

Difference Cordial labeling on the web graph for communicating some messages using a single method of numbering of alphabets $(D D C C)$ and one method for letter coding and a suitable matrix coding are given in this paper. The catchy clue, mathematical or non mathematical, using numbers and words for finding the suitable Web graph is given are meant to maintain secrecy and to induce interest. Matrix coding is also done. The researchers believe that in order to code a highly secretive message (official or pertaining to military services) the techniques discussed in this paper can be made use of. In the future, more coding techniques using different labeling on a web graph are planned to be done.

\section{REFERENCES}

[1] M.R. Joshi, R.A. Karkade, Network Security with Cryptography, Int. J. Computer Sci. Mob. Comput. 4 (1) 2015, 201 - 204.

[2] R. Ponraj, S.S. Narayanan, R. Kala, Difference cordiality of product related graphs, Tbilisi Math. J. 8 (2) (2015), 41-47.

[3] R.C. Read, Graph Theory and the Amateur Cryptographer, Computer Math. Appl. 34 (11) (1997), 121-127.

[4] P. Rizwan Ahmed, Cryptography Network Security and Cryptography, ISBN: 978-93-83242-07-2.

[5] S. Caminiti, I. Finocchi, R. Peterschi, On Coding Labeled Trees, Theor. Computer Sci. 382 (2007), 97 - 108.

[6] R. Ponraj, S.S. Narayanan, R. Kala, Difference Cordial labeling of graphs, Glob. J. Math. Sci. Theory Pract. 5 (3) (2013), 185-196.

[7] G. Uma Maheswari, G. Margaret Joan Jebarani, V. Balaji, Coding Through a Two Star and Super Mean Labeling, in: B. Rushi Kumar, R. Sivaraj, B.S.R.V. Prasad, M. Nalliah, A.S. Reddy (Eds.), Applied Mathematics and Scientific Computing, Springer International Publishing, Cham, 2019: pp. 469-478.

[8] G. Uma Maheswari, G. Margaret Joan Jebarani and V. Balaji, GMJ Coding Through a Three Star and Super Mean Labeling, American International Journal of Research in Science, Technology, Engineering \& Mathematics, ISSN print : 2328-3491, 2019.

[9] G. Uma Maheswari, G. Margaret Joan Jebarani and V. Balaji, GMJ Coding Through a Three Star and Super Mean Labeling, Amer. Int. J. Res. Sci. Technol. Eng. Math. Accepted.

[10] G. Uma Maheswari, J. Arthy, S.J. Obaiys, A Method of Secret Coding Technique on Two Star Graphs, Int. J. Computer Appl. 177 (39) (2020), 11-15.

[11] G. Uma Maheswari, S.J. Obaiys, Arthy, Coding Technique through Graph Labelings with the numbering of alphabets, MedRead J. Food Sci. 1 (2020), id1001. 
[12] S.K. Vaidya, C.M. Barasara, Edge Product Cordial Labeling of graphs, J. Math. Comput. Sci. 2 (2012), 1436-1450. 